This is an author produced version of a paper published in Lancet Neurology. This paper has been peer-reviewed but does not include the final publisher proof-corrections or journal pagination.

Citation for the published paper:

Hansson O, Zetterberg H, Buchhave P, Londos E, Blennow K, Minthon L

"Association between CSF biomarkers and incipient Alzheimer's disease in patients with mild cognitive impairment: a follow-up study"

Lancet Neurology, 2006, Vol: 5, Issue: 3, pp. 228-234. http://dx.doi.org/10.1016/S1474-4422(06)70355-6

Access to the published version may require journal subscription.

Published with permission from: Elsevier 


\section{Association between CSF biomarkers and incipient Alzheimer's disease in patients with mild cognitive impairment: a follow-up study}

Oskar Hansson, Henrik Zetterberg, Peder Buchhave, Elisabet Londos, Kaj

Blennow, Lennart Minthon

Clinical Memory Research Unit, Department of Clinical Sciences Malmö, Lund University, Sweden (O Hansson MD, P Buchhave MD, E Londos MD, L Minthon MD);

Neuropsychiatric Clinic, Malmö University Hospital, Sweden (O Hansson, P Buchhave, E Londos L Minthon); Institute of Clinical Neuroscience, Department of Experimental Neuroscience, Sahlgrenska University Hospital, Göteborg University, Sweden (H Zetterberg MD, K Blennow MD); and Department of Clinical Chemistry and Transfusion Medicine, Sahlgrenska University Hospital, Göteborg University, Sweden (K Blennow, H Zetterberg)

Correspondence to: Prof Kaj Blennow, Institute of Clinical Neuroscience, Department of Experimental Neuroscience, Sahlgrenska University Hospital, Mölndal S-431 80 Göteborg, Swedenkaj.blennow@neuro.gu.se 


\section{Summary}

Background Disease-modifying treatment strategies for Alzheimer's disease have led to an urgent need for biomarkers to identify the disease at a very early stage. Here, we assess the association between CSF biomarkers and incipient Alzheimer's in patients with mild cognitive impairment (MCI).

Methods From a series of 180 consecutive patients with MCI, we assessed 137 who underwent successful lumbar puncture at baseline. Patients at risk of developing dementia were followed clinically for 4-6 years. Additionally, 39 healthy individuals, cognitively stable over 3 years, served as controls. We analysed CSF concentrations of $\beta \operatorname{amyloid}_{1-42}(\mathrm{~A} \beta 42)$, total tau (T-tau), and phosphorylated tau (P-tau181) using Luminex xMAP technology. Findings During follow-up, 57 (42\%) patients with MCI developed Alzheimer's disease, 21 $(15 \%)$ developed other forms of dementia, and 56 (41\%) remained cognitively stable for $5 \cdot 2$ years (range $4 \cdot 0-6 \cdot 8$ ). A combination of CSF T-tau and A $\beta 42$ at baseline yielded a sensitivity of $95 \%$ and a specificity of $83 \%$ for detection of incipient AD in patients with MCI. The relative risk of progression to Alzheimer's disease was substantially increased in patients with MCI who had pathological concentrations of T-tau and A $\beta 42$ at baseline (hazard ratio 17.7, $\mathrm{p}<0.0001)$. The association between pathological CSF and progression to Alzheimer's disease was much stronger than, and independent of, established risk factors including age, sex, education, APOE genotype, and plasma homocysteine. The combination of T-tau and A $\beta$ 42/P-tau 181 ratio yielded closely similar results (sensitivity $95 \%$, specificity $87 \%$, hazard ratio 19·8).

Interpretation Concentrations of T-tau, P-tau181, and A $\beta 42$ in CSF are strongly associated with future development of Alzheimer's disease in patients with MCI. 


\section{Introduction}

Alzheimer's disease (AD) is the most common cause of dementia. The prevalence of dementia doubles every 5 years from the age of 65 so that around $40 \%$ in the age group $90-95$ years are affected. With increasing life expectancy across the world, dementia is a rapidly growing socio-economical and medical problem. ${ }^{1}$ The pathogenic process of AD probably starts decades before the clinical onset of the disease. ${ }^{2}$ During this pre-clinical period there is a gradual loss of axons and neurons and at a certain threshold the first symptoms, most often impaired episodic memory, appear. These patients do not fulfil the criteria for dementia and may be diagnosed with mild cognitive impairment (MCI). However, MCI is a very common syndrome in elderly and the aetiology is heterogeneous. Even though around 40 to $60 \%$ of the MCI patients develop AD during the first 5 years, many subjects have a stable form of memory impairment. ${ }^{3,4}$ Moreover, early stages of e.g. vascular dementia (VaD) or dementia with Lewy bodies (DLB) can be preceded by MCI. ${ }^{4}$ Depression may also mimic the condition. To date, there is no established method to predict progression to AD among individuals with MCI. Hence, new tools to aid in the diagnostic work-up of individuals with MCI would be of fundamental public health importance. Such tools would be of even greater significance if new drug candidates such as $\beta$-sheet breakers, $\beta$ - and $\gamma$-secretase inhibitors and $\mathrm{A} \beta$ immunotherapy prove to have disease-arresting effects. These types of drugs are likely to have the best efficacy in the early or even pre-clinical phase of the disease, when the synaptic and neuronal loss has not become too widespread. ${ }^{5,6}$ In fact, lack of tools to detect pre-clinical $\mathrm{AD}$ has been suggested to be one of the main obstacles for the development of new anti-AD therapeutics. $^{7}$

Earlier studies indicate that cerebrospinal fluid (CSF) biomarkers may be useful for defining a subgroup of MCI patients at especially high risk of developing AD. ${ }^{5,8,9}$ However, the clinical follow-up in these studies has been short, generally only around 1 to 2 years. ${ }^{5,8,9}$ Given that 8 $15 \%$ of the MCI cases progress to AD each year, a very extensive follow-up period ( $>4-5$ years) would be needed to ascertain whether a stable MCI patient really does not suffer from incipient AD. ${ }^{5}$ Moreover, when assessing the accuracy of a diagnostic test, the study should preferably include a consecutive series of patients from a relevant clinical population. ${ }^{10-12}$ However, the MCI subjects included in CSF studies have generally been highly selected, e.g. by inclusion of only those MCI patients that progress to AD and exclusion of MCI subjects with signs of cerebrovascular disease or depression. ${ }^{5}$ Furthermore, so far only one CSF study 
has investigated a consecutive series of MCI patients, in which $57 \mathrm{MCI}$ subjects were followed for an average of 2 years. ${ }^{9}$ In that study, only CSF T-tau was analysed.

In order to study the association between CSF biomarkers and incipient AD in a clinically relevant, heterogeneous population of MCI subjects, we evaluated a consecutive series of 180 patients with MCI. Out of these, 137 (76\%) underwent lumbar puncture at baseline, and were included in the study. The MCI patients were followed clinically at least until they developed a certain type of dementia or until they had been cognitively stable for a median of $5 \cdot 2$ (range 4.0-6.8) years. The ability of CSF biomarkers at baseline to predict AD was assessed. Furthermore, the predictive value of CSF biomarkers was compared to other known risk factors for $\mathrm{AD}$. To our knowledge, this is the largest study, with the longest average follow-up time, evaluating CSF biomarkers in MCI patients. Furthermore, the MCI patients were recruited consecutively in order to reduce ascertainment and participation bias. 


\section{Materials and Methods}

\section{MCI subjects at baseline}

All patients who consulted the memory disorder clinic at Malmö University Hospital, Sweden, between July 1998 and June 2001, were screened for MCI. Most patients (75\%) were referred to the clinic by general practitioners. This approach resulted in detection of 180 consecutive subjects with MCI, all of whom were evaluated in the initial clinical study. At baseline, experienced physicians specialized in cognitive disorders, examined the patients with physical, neurological and psychiatric examination, careful clinical history and functional assessment. Moreover, routine blood analyses, analysis of apolipoprotein E (APOE) genotype, blood pressure, computed tomography (CT) of the brain and cognitive tests (e.g. Mini-Mental State Examination [MMSE], ${ }^{13}$ the Alzheimer's Disease Assessment Scalecognitive subscale [ADAS-cog], ${ }^{14}$ and the clock-drawing test ${ }^{15}$ ) were performed. The criteria of MCI were those defined by Petersen and collaborators, ${ }^{4,16}$ which include: (i) memory complaint, preferably corroborated by an informant, (ii) objective memory impairment adjusted for age and education, (iii) preservation of general cognitive functioning (iv) no or minimal impairment of daily life activities, and (v) not fulfilling the DSM-IIIR (Diagnostic and Statistical Manual of Mental Disorders, $3^{\text {rd }}$ edition, revised) criteria of dementia. ${ }^{17}$ Patients with other causes of cognitive impairment, including brain tumour, subdural haematoma, CNS infection, and current alcohol abuse were excluded. However, it is very important to include a clinically relevant population of subjects with MCI, which reflects the normal clientele in a memory clinic $^{10}$, even though such an MCI population is heterogeneous. Therefore, the MCI subjects were allowed to exhibit white matter changes or silent brain infarcts, because these changes are common in elderly subjects with or without cognitive deficits. ${ }^{18}$ Similarly, depressive symptoms and low plasma concentrations of vitamin B12 or folate were treated at baseline, but we did not exclude these patients from the study. ${ }^{19}$

All patients gave informed consent to participate in the study. The study was conducted according to the provisions of the Helsinki Declaration and was approved by the ethics committee of Lund University, Sweden.

\section{Follow-up of MCI subjects}

The patients were followed by experienced physicians, specialized in cognitive disorders, at least until they developed a certain type of dementia or until they had been cognitively stable 
for more than 4 years (median 5.2 years; range 4.0-6.8 years). The patients that received a diagnosis of AD during follow-up were required to meet the DSM-IIIR criteria of dementia, ${ }^{17}$ and the criteria of "probable" AD defined by NINCDS-ADRDA (National Institute of Neurological and Communicative Disorders - Stroke/Alzheimer's Disease and Related Disorders Association). ${ }^{20}$ The median follow-up time for patients that developed AD was $4 \cdot 3$ (range 1.1-6.7 years). The patients that received a diagnosis of $\mathrm{VaD}$ fulfilled the DSM-IIIR criteria of dementia, ${ }^{17}$ and the requirements of NINDS-AIREN (National Institute of Neurological Disorders and Stroke - Association Internationale pour la Recherche et 1'Enseignement en Neurosciences) for probable $\mathrm{VaD} .{ }^{21}$ For patients that developed DLB or frontotemporal dementia (FTD) the consensus criteria by McKeith and collaborators, ${ }^{22}$ and Brun and colleagues, ${ }^{23}$ were used, respectively. The median follow-up time for the patients that developed dementias other than $\mathrm{AD}$ was $4 \cdot 2$ (range $1 \cdot 5-6 \cdot 3$ years).

\section{Control subjects}

The control population consisted of 39 healthy volunteers, all of whom underwent lumbar puncture at baseline. The controls were recruited in the city of Malmö, Sweden. Inclusion criteria were (i) absence of memory complaints or any other cognitive symptoms, (ii) preservation of general cognitive functioning, and (iii) no active neurological or psychiatric disease. Individuals with other medical conditions not affecting cognition were not excluded. Just as for the MCI subjects, the controls were followed over time and those included were cognitively stable, as judged clinically and by neuropsychological testing, for a follow-up period of 3 years.

\section{Analysis of CSF}

CSF was collected from 39 controls and 137 of the consecutive MCI subjects in polypropylene tubes, stored at $-80^{\circ} \mathrm{C}$ and analysed after the clinical follow-up of the study was completed. Only one patient reported moderate headache after the lumbar puncture. No other side effects were reported. Of the $43 \mathrm{MCI}$ patients that did not undergo successful lumbar puncture at baseline, 32 subjects preferred not to go through the procedure, and in 11 subjects the procedure failed to deliver usable CSF. Importantly, the physicians making the diagnosis during follow-up were blinded to all CSF analyses. Total-tau (T-tau), tau phosphorylated at threonine $181\left(\mathrm{P}-\operatorname{tau}_{181}\right)$ and $\beta$ - $\operatorname{amyloid}_{1-42}(\mathrm{~A} \beta 42)$ levels were determined using the xMAP technology and the INNO-BIA AlzBio3 kit (Innogenetics) as previously described in detail. ${ }^{24}$ In brief, this technology is based on flow cytometric separation of 
antibody-coated microspheres that are labelled with a specific mixture of two fluorescent dyes. After binding of a biotinylated reporter antibody, quantification is made by binding of a third fluorochrome coupled to streptavidin. The technique allows for simultaneous measurement of several analytes in the same tube. The CSF levels of T-tau, P-tau 181 and A $\beta 42$ are highly correlated to the levels obtained by conventional ELISA measurements. ${ }^{24}$ The bestcutting values for the different combinations of the CSF biomarkers were established in the whole control and MCI patient material as those giving the highest Youden index. ${ }^{25}$

\section{Data analysis}

To compare demographic, clinical and CSF baseline data between groups, a non-parametric Kruskal-Wallis ANOVA was performed followed by Mann-Whitney $U$-test for continuous variables. Pearson's $x^{2}$ test was used for dichotomous variables. The Spearman correlation coefficient was used for correlation analyses. The primary outcome of interest was time to conversion to AD. Pathological (or Alzheimer's disease-indicative) CSF was defined on the basis of cut-off values for three different combinations of baseline T-tau, A $\beta 42$ and P-tau 181 . Cox proportional hazards models were used to separately estimate the effects of different baseline risk factors on the relative risk of conversion from MCI to AD. The analyses were performed with and without adjustment for potential confounding of the baseline demographic variables, i.e. age, gender, education level and APOE $\varepsilon 4$ carrier status. Furthermore, a backward stepwise Cox regression model was used to simultaneously estimate the impact of all the baseline variables (pathological CSF, age, gender, APOE \&4 carrier status, education level, systolic blood pressure, diastolic blood pressure, plasma homocysteine, MMSE total score, MMSE delayed recall, clock-drawing test) on the conversion to AD among MCI subjects. Variables with $P>0 \cdot 10$ were removed from the stepwise model. Kaplan-Meier curves were used to illustrate the differences in progression to $\mathrm{AD}$ between MCI patients with normal and pathological CSF levels of T-tau and A $\beta 42$ at baseline. The statistical analyses were accomplished with SPSS for Windows, version $12 \cdot 0 \cdot 1$. 


\section{Results}

\section{Study population}

A consecutive series of 180 patients with mild cognitive impairment (MCI) were evaluated. They were between 50 and 86 years of age and 55\% were women. At baseline, 137 (76\%) of the subjects with MCI underwent successful lumbar puncture, and were included in the study. CSF was analysed after the clinical follow-up was completed. The patients that did not undergo lumbar puncture did not differ from those that underwent the procedure with regards to diagnosis after clinical follow-up, baseline MMSE score, gender or APOE genotype (data not shown).

Out of the 137 MCI subjects with CSF obtained at baseline, 56 were cognitively stable when followed for more than 4 years (median follow-up time, $5 \cdot 2$ years; range, 4·0-6.8 years).

Three subjects died before 4 years of follow-up. Due to uncertainty of their cognitive stability they were excluded from the study. During follow-up, 57 of the subjects with MCI at baseline developed AD. Moreover, $21 \mathrm{MCI}$ patients progressed to other forms of dementia, e.g. VaD (15 subjects) and DLB (3 subjects). Baseline demographic data are given in table 1.

\section{Baseline levels of CSF biomarkers}

The CSF levels at baseline of T-tau and P-tau 181 were significantly increased in the MCI patients that developed $\mathrm{AD}$ during follow-up, as compared to the controls, the cognitively stable MCI patients, and the MCI patients that developed other forms of dementia (MannWhitney $U$-test, $\mathrm{P}<0 \cdot 0001$ ) (Table 2), while $\mathrm{A} \beta 42$ was significantly decreased (MannWhitney $U$-test, $\mathrm{P}<0 \cdot 0001$ ) (Table 2). The levels of CSF tau and A $\beta 42$ did not correlate with age (Spearman correlation, $\mathrm{P}>0 \cdot 4$ ) or baseline MMSE score (Spearman correlation, $\mathrm{P}>0 \cdot 2$ ) in the control group. Similarly, the levels of the CSF biomarkers in the control population were not different between male and female subjects (Mann Whitney U-test, P >0.30) or between $A P O E \varepsilon 4$ allele carriers and non-carriers (Mann Whitney U-test, $\mathrm{P}>0 \cdot 15$ ).

\section{Association between a combination of T-tau and A 342 and incipient $A D$}

To predict conversion from MCI to $\mathrm{AD}$, the combination of T-tau and $\mathrm{A} \beta 42$ in the baseline CSF was used. The cut-off values that best detected incipient AD were T-tau $>350 \mathrm{ng} / \mathrm{L}$ and A $\beta 42<530 \mathrm{ng} / \mathrm{L}$, which defined pathological (or AD-indicative) CSF. At baseline 67 (50\%) of MCI cases fulfilled this criterion. Using this definition, the specificity in the cognitively 
stable control population was $92 \%$. In our MCI population, the combined test yielded a sensitivity of $95 \%$ and specificity of $83 \%$ for prediction of AD during 4-6 years follow-up (Figure 1A). The positive predictive value was $81 \%$ and the negative predictive value was $96 \%$ for progression to $\mathrm{AD}$.

The Kaplan-Meier estimates of the probability of conversion to AD in MCI subjects with either normal or pathological CSF at baseline, as defined above, are demonstrated in figure 3. The univariate Cox proportional hazards model showed that there was a significant difference in the probability of progression from MCI to AD between the subjects with pathological CSF and those with normal CSF at baseline (hazard ratio [HR] 30.0 (95\% CI, 9.32-96.8; P< 0.0001) (Table 3; Figure 2). Demographic risk factors may modify the association between pathological CSF and progression to AD. However, pathological CSF was still a very strong risk factor for future development of $\mathrm{AD}$ after adjustment for age, sex, education level and APOE genotype (HR 17.7 (95\% CI, 5.33-58.9; $P<0.0001)$ (Table 3). Furthermore, the risk factors were analysed simultaneously using a multivariate backward stepwise Cox regression model. In this stepwise model, pathological CSF, age, female gender and plasma homocysteine were significantly associated with progression to AD among MCI subjects, while the other risk factors did not contribute to the explanatory power of the model.

Association between different combinations of T-tau, P-tau ${ }_{181}$ and $A \beta 42$ and incipient $A D$ The combination of baseline P-tau $181>60 \mathrm{ng} / \mathrm{L}$ and A $\beta 42<530 \mathrm{ng} / \mathrm{L}$ (69 [52\%] individuals fulfilled this criterion), resulted in a sensitivity of $95 \%$ and a specificity of $81 \%$ for prediction of $\mathrm{AD}$ among patients with MCI (Figure 1B). The Cox proportional hazard ratio was 26.3 (95\% CI, 8.16-84.5; $P<0.0001)$ for progression from MCI to AD, while the adjusted hazard ratio was $16.8(95 \% \mathrm{CI}, 5.02-56.5 ; P<0.0001)$.

When using the combination of $\mathrm{T}-\mathrm{tau}$ and $\mathrm{A} \beta 42 / \mathrm{P}-\operatorname{tau}_{181}$ ratio, the optimal cut-off values were $>350 \mathrm{ng} / \mathrm{L}$ for T-tau and $<65$ for the $\mathrm{A} \beta 42 / \mathrm{P}-\operatorname{tau}_{181}$ ratio. Sixty-four (48\%) individuals fulfilled this criterion. The sensitivity and specificity for prediction of AD in MCI subjects were $95 \%$ and $87 \%$, respectively (Figure 1C). The hazard ratio was 32.8 (95\% CI, 10.2-105.6; $P<0.0001)$, while the adjusted hazard ratio was 19.8 (95\% CI, 5.99-65.7; $P<0.0001)$ (Table $3)$. 
Change of CSF biomarkers as an early event in $A D$

Finally, we analysed whether there was an association between the baseline levels of T-tau, P$\operatorname{tau}_{181}$ or $\mathrm{A} \beta 42$, and the time period to conversion to AD. Among the MCI subjects that developed $\mathrm{AD}$ during follow-up, there was no correlation between the time to conversion to $\mathrm{AD}$ and the levels of any of the CSF biomarkers (Spearman correlation, $P>0 \cdot 5$ ), i.e. the levels of T-tau, P-tau 181 and $A \beta 42$ were equally changed in patients that developed AD after 5 years as in subjects that progressed to $\mathrm{AD}$ within 1 year. These results indicate that changes in the levels of CSF tau and A $\beta 42$ are early events in the pathogenesis of AD. 


\section{Discussion}

The introduction of acetylcholine esterase inhibitors for symptomatic treatment has highlighted the importance of diagnostic markers for incipient AD. People's awareness of the availability of drug treatment has resulted in patients seeking medical advice at an earlier stage of the disease, making the percentage of MCI cases at memory disorder clinics increase. To date there is no diagnostic method to determine if $\mathrm{MCI}$ in a certain patient will progress to $\mathrm{AD}$ with dementia, remain stable or deteriorate to other dementia types. ${ }^{5,7}$ Such diagnostic tools will be very important when evaluating the effects of potentially disease-arresting treatments, since such therapies will probably be more efficient if initiated before widespread neuronal death and dysfunction is already established. Interestingly, two recent studies, using transgenic mice, have shown that tau pathology is only reversible if intervention occurs early in the disease process. ${ }^{26,27}$ Thus, there is a great need to find diagnostic tools to identify incipient $\mathrm{AD}$ among subjects with MCI.

In this clinically based study, a consecutive series of 137 patients with MCI were included and CSF was obtained at baseline. The MCI patients were followed clinically for an average of more than five years. A combination of baseline CSF T-tau and A $\beta 42$ yielded a sensitivity of $95 \%$ and a specificity of $83 \%$ for detection of incipient AD among MCI patients. When using combination of $\mathrm{T}$-tau and the $\mathrm{A} \beta 42 / \mathrm{P}_{181}$-tau ratio, ${ }^{28,29}$ the specificity was slightly higher. However, more studies are needed to answer the question which combination has the best performance, since the differences in our study were subtle. The predictive power of all the different combinations of CSF biomarkers was much stronger than, and independent of, other established risk factors such as age, gender, education, APOE genotype, plasma homocysteine, blood pressure and low performance on brief cognitive tests.

Corroborating earlier data, ${ }^{5,8,30} \mathrm{MCI}$ patients with progression to $\mathrm{AD}$ had an increased baseline level of T-tau and P-tau 181 , while the level of A $\beta 42$ was decreased. However, our study differs from previous studies in that both the MCI patients and controls were followed for a long time. Thus, the diagnosis of stable MCI is more reliable in this study compared to previous investigations. ${ }^{5,8,9}$ However, an even more extensive follow-up time ( $>5$ years) of the stable MCI subjects than in our study might increase the specificity of CSF biomarkers further, because some of the stable MCI cases with pathological CSF might still develop AD later on. 
The specificity of the combination of CSF T-tau and A $\beta 42$ was $92 \%$ in our control group, and $90 \%$ when the same cut-off levels were applied in a previously published control population consisting of 53 healthy subjects. ${ }^{24}$ This specificity level may be acceptable considering that approximately $5-10 \%$ of control subjects might develop AD within 10 years time. ${ }^{31}$

It is important to note that the cut-off levels differ between different studies. This is a general problem, probably caused by the lack of external control programmes for CSF biomarkers, resulting in unsatisfactory standardization of biomarker levels between different laboratories. Another problem is the use of different principles for establishing cut-offs between studies. Thus, there are no accepted cut-off values for MCI (or AD) populations. An external control programme is under planning as a part of the Alzheimer's disease neuroimaging (ADNI) project both in the US and in Europe.

To our knowledge, this study has the largest sample size and the most extensive clinical follow-up, including many different diagnostic modalities. Further, the study population was recruited consecutively, which reduces the risk of ascertainment and participation bias. ${ }^{10-12}$ The study also reflects the heterogeneity of MCI patients in the clinic, because MCI patients with depressive symptoms or vascular risk factors at baseline were also included. ${ }^{18,19}$ The inclusion of MCI patients with vascular risk factors, e.g. silent brain infarcts, might account for the fact that some MCI subjects developed VaD during follow-up. Last, we compare the predictive power of CSF biomarkers with other established risk factors for AD. It should be noted, however, that although some selected variables were controlled for, there might still be factors confounding the association between CSF biomarkers and incipient AD. Nevertheless, the achieved results are relevant both to clinicians working with MCI patients and to researchers designing clinical trials of anti-AD drugs with possible disease-arresting effects.

Neuroimaging methods and cognitive tests might aid in detection of incipient AD among MCI cases. However, a crucial problem with these methods is that the reliability of each is a function of disease severity, and therefore as we attempt to identify individuals at progressively earlier stages of the disease there is a risk of increasing overlap between subjects with incipient $\mathrm{AD}$ and those with normal aging, psychiatric illness or incipient vascular dementia. ${ }^{32}$ Recent magnetic resonance imaging (MRI) studies indicate that brain atrophy is associated with increased risk of conversion from MCI to AD, with hazard ratios of 
around $1 \cdot 5-3 \cdot 0 .{ }^{33,34}$ However, the overlap in these studies between cases with or without AD at follow-up indicates that MRI is unlikely to provide absolute prognostic information for individual MCI patients. ${ }^{33,34}$ On the contrary, as our study indicates, molecular changes that can be measured in the CSF are probably well underway when the earliest symptoms of AD become clinically manifest.

Taken together, our results show that CSF analyses of T-tau, P-tau 181 and A $\beta 42$ are strong and independent risk markers for development of clinical AD among MCI patients. If validated in other consecutive studies with long follow-up, these results may have an impact both on the diagnostic work-up and on the design of clinical trials of patients with MCI. Furthermore, some previous studies indicate that CSF biomarkers may identify AD preclinically, even before the onset of MCI. ${ }^{35-37}$ The same may hold true for positron emission tomography (PET) and functional MRI. ${ }^{38,39}$ In clinical drug trials with follow-up periods of 3-4 years, around $50-80 \%$ of MCI patients do not develop $\mathrm{AD}^{40,41}$ It may be considered unethical to include large numbers of MCI patients that do not have incipient AD in treatment trials on the new kind of disease-modifying drug candidates, such as A $\beta$ immunotherapy, that may involve a risk of serious side effects. ${ }^{42}$ Moreover, the beneficial effects of a treatment might be more difficult to detect in such heterogeneous populations of MCI patients. In the future, CSF, MRI and PET biomarkers may be valuable tools to enrich clinical MCI trials with cases at high risk of developing AD. 


\section{Acknowledgements}

This work was supported by grants from the Swedish Medical Research Council (project \#14002), the Swedish Council for Working Life and Social Research, the Göteborg Medical Society, the Swedish Medical Society, the Swedish Society for Medical Research, Swedish Brain Power, Stiftelsen Gamla Tjänarinnor and Alzheimerfonden.

\section{Authors' contributions}

O.H., and L.M. had the idea for this particular study and participated in the conception and design of the study. O.H., P.B. and E.L. participated in the acquisition of clinical data and interpreting the data. K.B. and H.Z. were responsible for the analysis of CSF and interpreting the data. O.H. and H.Z drafted the paper. K.B., L.M., P.B and E.L made important revisions to the manuscript.

\section{Conflicts of interest}

$\mathrm{KB}$ has on one occasion received a consulting fee for an Advisory Board meeting from Innogenetics, but has no other conflicts of interest. OH, HZ, PB, EL, and LM have no conflicts of interest.

\section{Role of the funding source}

The sponsors of the study had no role in study design, data collection, data analysis, data interpretation, or writing of the report. The corresponding author had full access to all the data in the study and had final responsibility for the decision to submit for publication. 


\section{References}

1 Ferri CP, Prince M, Brayne C, Brodaty H, Fragtiglioni L, Ganguli M, Hall K, Hasegawa

K, Hendrie H, Huang Y, Jorm AF, Mathers C, Menezes PR, Rimmer E, Scazufca M. Global prevalence of dementia: a Delphi consensus study. Lancet 2005; 366: 2112-7.

2 Price JL, Morris JC. Tangles and plaques in nondemented aging and "preclinical" Alzheimer's disease. Ann Neurol 1999; 45: 358-68.

3 DeCarli C. Mild cognitive impairment: prevalence, prognosis, aetiology, and treatment. Lancet Neurol 2003; 2: 15-21.

4 Petersen RC. Mild cognitive impairment as a diagnostic entity. J Intern Med 2004; 256: 183-94.

5 Blennow K, Hampel H. CSF markers for incipient Alzheimer's disease. Lancet Neurol 2003; 2: 605-13.

6 DeKosky ST, Marek K. Looking backward to move forward: early detection of neurodegenerative disorders. Science 2003; 302: 830-4.

7 Lansbury PT, Jr. Back to the future: the 'old-fashioned' way to new medications for neurodegeneration. Nat Med 2004; 10 (suppl): S51-7.

8 Hampel H, Teipel SJ, Fuchsberger T, Andreasen N, Wiltfang J, Otto M, Shen Y, Dodel R, Du Y, Farlow M, Moller HJ, Blennow K, Buerger K. Value of CSF beta-amyloid1-42 and tau as predictors of Alzheimer's disease in patients with mild cognitive impairment. Mol Psychiatry 2004; 9: 705-10.

9 Maruyama M, Matsui T, Tanji H, Nemoto M, Tomita N, Ootsuki M, Arai H, Sasaki H. Cerebrospinal fluid tau protein and periventricular white matter lesions in patients with mild cognitive impairment: implications for 2 major pathways. Arch Neurol 2004; 61: 716-20. 
10 Lijmer JG, Mol BW, Heisterkamp S, Bonsel GJ, Prins MH, van der Meulen JH, Bossuyt PM. Empirical evidence of design-related bias in studies of diagnostic tests. JAMA 1999; 282: 1061-6.

11 Irwig L, Tosteson AN, Gatsonis C, Lau J, Colditz G, Chalmers TC, Mosteller F. Guidelines for meta-analyses evaluating diagnostic tests. Ann Intern Med 1994; 120: 667-76.

12 Reid MC, Lachs MS, Feinstein AR. Use of methodological standards in diagnostic test research. Getting better but still not good. JAMA 1995; 274: 645-51.

13 Folstein MF, Folstein SE, McHugh PR. "Mini-mental state". A practical method for grading the cognitive state of patients for the clinician. J Psychiatr Res 1975; 12: 189-98.

14 Mohs RC, Knopman D, Petersen RC, Ferris SH, Ernesto C, Grundman M, Sano M, Bieliauskas L, Geldmacher D, Clark C, Thal LJ. Development of cognitive instruments for use in clinical trials of antidementia drugs: additions to the Alzheimer's Disease Assessment Scale that broaden its scope. The Alzheimer's Disease Cooperative Study. Alzheimer Dis Assoc Disord 1997; 11 (suppl 2): S13-21.

15 Manos PJ, Wu R. The ten point clock test: a quick screen and grading method for cognitive impairment in medical and surgical patients. Int J Psychiatry Med 1994; 24: 22944.

16 Petersen RC, Smith GE, Waring SC, Ivnik RJ, Tangalos EG, Kokmen E. Mild cognitive impairment: clinical characterization and outcome. Arch Neurol 1999; 56: 303-8.

17 American Psychiatric Association. Diagnostic and Statistical Manual of Mental Disorders. Third Edition, Revised. 1987.

18 Vermeer SE, Prins ND, den Heijer T, Hofman A, Koudstaal PJ, Breteler MM. Silent brain infarcts and the risk of dementia and cognitive decline. $N$ Engl J Med 2003; 348: 1215-22. 
19 Visser PJ, Scheltens P, Verhey FR. Do MCI criteria in drug trials accurately identify subjects with predementia Alzheimer's disease? J Neurol Neurosurg Psychiatry 2005; 76: $1348-54$.

20 McKhann G, Drachman D, Folstein M, Katzman R, Price D, Stadlan EM. Clinical diagnosis of Alzheimer's disease: report of the NINCDS-ADRDA Work Group under the auspices of Department of Health and Human Services Task Force on Alzheimer's Disease. Neurology 1984; 34: 939-44.

21 Roman GC, Tatemichi TK, Erkinjuntti T, Cummings JL, Masdeu JC, Garcia JH, Amaducci L, Orgogozo JM, Brun A, Hofman A, et al. Vascular dementia: diagnostic criteria for research studies. Report of the NINDS-AIREN International Workshop. Neurology 1993; 43: $250-60$.

22 McKeith IG, Perry EK, Perry RH. Report of the second dementia with Lewy body international workshop: diagnosis and treatment. Consortium on Dementia with Lewy Bodies. Neurology 1999; 53: 902-5.

23 Brun A, Englund E, Gustafson L, Passant U, Mann D, Neary D, Snowden J. Clinical and neuropathological criteria for frontotemporal dementia. J Neurol Neurosurg Psychiatry 1994; 57: 416-8.

24 Olsson A, Vanderstichele H, Andreasen N, De Meyer G, Wallin A, Holmberg B, Rosengren L, Vanmechelen E, Blennow K. Simultaneous measurement of beta-amyloid(142), total tau, and phosphorylated tau (Thr181) in cerebrospinal fluid by the XMAP technology. Clin Chem 2005; 51: 336-45.

25 Youden WJ. Index for rating diagnostic tests. Cancer 1950; 3: 32-5.

26 Oddo S, Billings L, Kesslak JP, Cribbs DH, LaFerla FM. Abeta immunotherapy leads to clearance of early, but not late, hyperphosphorylated tau aggregates via the proteasome. Neuron 2004; 43: 321-32. 
27 Santacruz K, Lewis J, Spires T, Paulson J, Kotilinek L, Ingelsson M, Guimaraes A, DeTure M, Ramsden M, McGowan E, Forster C, Yue M, Orne J, Janus C, Mariash A, Kuskowski M, Hyman B, Hutton M, Ashe KH. Tau suppression in a neurodegenerative mouse model improves memory function. Science 2005; 309: 476-81.

28 Maddalena A, Papassotiropoulos A, Muller-Tillmanns B, Jung HH, Hegi T, Nitsch RM, Hock C. Biochemical diagnosis of Alzheimer disease by measuring the cerebrospinal fluid ratio of phosphorylated tau protein to beta-amyloid peptide42. Arch Neurol 2003; 60: 1202-6.

29 Ibach B, Binder H, Dragon M, Poljansky S, Haen E, Schmitz E, Koch H, Putzhammer A, Kluenemann H, Wieland W, Hajak G. Cerebrospinal fluid tau and beta-amyloid in Alzheimer patients, disease controls and an age-matched random sample. Neurobiol Aging 2005; [Epub ahead of print].

30 Herukka SK, Hallikainen M, Soininen H, Pirttila T. CSF Abeta42 and tau or phosphorylated tau and prediction of progressive mild cognitive impairment. Neurology 2005; 64: 1294-7.

31 Jorm AF, Jolley D. The incidence of dementia: a meta-analysis. Neurology 1998; 51: $728-33$.

32 Nestor PJ, Scheltens P, Hodges JR. Advances in the early detection of Alzheimer's disease. Nat Med 2004; 10 (suppl): S34-41.

33 Jack CR, Jr., Shiung MM, Weigand SD, O'Brien PC, Gunter JL, Boeve BF, Knopman DS, Smith GE, Ivnik RJ, Tangalos EG, Petersen RC. Brain atrophy rates predict subsequent clinical conversion in normal elderly and amnestic MCI. Neurology 2005; 65: 1227-31.

34 Korf ES, Wahlund LO, Visser PJ, Scheltens P. Medial temporal lobe atrophy on MRI predicts dementia in patients with mild cognitive impairment. Neurology 2004; 63: 94-100.

35 Skoog I, Davidsson P, Aevarsson O, Vanderstichele H, Vanmechelen E, Blennow K. Cerebrospinal fluid beta-amyloid 42 is reduced before the onset of sporadic dementia: a population-based study in 85-year-olds. Dem Geriatr Cogn Disord 2003; 15: 169-76. 
36 Moonis M, Swearer JM, Dayaw MP, St George-Hyslop P, Rogaeva E, Kawarai T, Pollen DA. Familial Alzheimer disease: decreases in CSF Abeta42 levels precede cognitive decline. Neurology 2005; 65: 323-5.

37 Sunderland T, Mirza N, Putnam KT, Linker G, Bhupali D, Durham R, Soares H, Kimmel L, Friedman D, Bergeson J, Csako G, Levy JA, Bartko JJ, Cohen RM. Cerebrospinal fluid beta-amyloid1-42 and tau in control subjects at risk for Alzheimer's disease: the effect of APOE epsilon4 allele. Biol Psychiatry 2004; 56: 670-6.

38 Reiman EM, Caselli RJ, Yun LS, Chen K, Bandy D, Minoshima S, Thibodeau SN, Osborne D. Preclinical evidence of Alzheimer's disease in persons homozygous for the epsilon 4 allele for apolipoprotein E. $N$ Engl J Med 1996; 334: 752-8.

39 Bookheimer SY, Strojwas MH, Cohen MS, Saunders AM, Pericak-Vance MA, Mazziotta JC, Small GW. Patterns of brain activation in people at risk for Alzheimer's disease. $N$ Engl J Med 2000; 343: 450-6.

40 Thal LJ, Ferris SH, Kirby L, Block GA, Lines CR, Yuen E, Assaid C, Nessly ML, Norman BA, Baranak CC, Reines SA. A randomized, double-blind, study of rofecoxib in patients with mild cognitive impairment. Neuropsychopharmacology 2005; 30: 1204-15.

41 Petersen RC, Thomas RG, Grundman M, Bennett D, Doody R, Ferris S, Galasko D, Jin S, Kaye J, Levey A, Pfeiffer E, Sano M, van Dyck CH, Thal LJ. Vitamin E and donepezil for the treatment of mild cognitive impairment. N Engl J Med 2005; 352: 2379-88.

42 Orgogozo JM, Gilman S, Dartigues JF, Laurent B, Puel M, Kirby LC, Jouanny P, Dubois B, Eisner L, Flitman S, Michel BF, Boada M, Frank A, Hock C. Subacute meningoencephalitis in a subset of patients with AD after Abeta42 immunization. Neurology 2003; 61: 46-54. 


\section{Tables}

Table 1. Baseline demographic data and annual change of MMSE during follow-up of patients with MCI and healthy controls with CSF obtained at baseline.

\begin{tabular}{|l|l|l|l|l|l|l|}
\hline & M/W & $\begin{array}{l}\text { Age at } \\
\text { baseline, } \\
\text { median (range) }\end{array}$ & $\begin{array}{l}\text { APOE } \varepsilon 4 \\
\text { carrier, } \%\end{array}$ & $\begin{array}{l}\text { Higher } \\
\text { education, } \\
\%\end{array}$ & $\begin{array}{l}\text { MMSE at } \\
\text { baseline }\end{array}$ & $\begin{array}{l}\text { Annual } \\
\text { change of } \\
\text { MMSE }\end{array}$ \\
\hline Controls & $15 / 24$ & $72(60-87)$ & $10(26 \%)$ & $17(44 \%)$ & $29 \cdot 1 \pm 1 \cdot 0$ & $+0 \cdot 1 \pm 0 \cdot 4$ \\
\hline Stable MCI & $30 / 26$ & $67(50-86)^{\mathrm{a}}$ & $28(50 \%)^{\mathrm{b}}$ & $26(46 \%)$ & $27 \cdot 3 \pm 1 \cdot 8^{\mathrm{a}}$ & $+0 \cdot 2 \pm 0 \cdot 4$ \\
\hline MCI-AD & $16 / 41^{\mathrm{c}}$ & $75(59-85)^{\mathrm{d}}$ & $43(75 \%)^{\mathrm{a}, \mathrm{e}}$ & $18(32 \%)$ & $26 \cdot 8 \pm 1 \cdot 4^{\mathrm{a}}$ & $-3 \cdot 0 \pm 2 \cdot 4^{\mathrm{a}, \mathrm{d}}$ \\
\hline MCI-other & $14 / 7^{\mathrm{f}}$ & $76(54-82)^{\mathrm{g}}$ & $6(29 \%)$ & $10(48 \%)$ & $27 \cdot 0 \pm 1 \cdot 5^{\mathrm{a}}$ & $-2 \cdot 5 \pm 2 \cdot 3^{\mathrm{a}, \mathrm{d}}$ \\
\hline
\end{tabular}

Values are means $\pm \mathrm{SD}$, except as noted otherwise.

${ }^{\mathrm{a}} P<0.0001$ vs. Controls; ${ }^{\mathrm{b}} P=0.03$ vs. Controls; ${ }^{\mathrm{c}} P=0.01$ vs. Stable MCI; ${ }^{\mathrm{d}} P<0 \cdot 0001$ vs. Stable MCI; ${ }^{\mathrm{e}} P=0.009$ vs. Stable MCI; ${ }^{\mathrm{f}} P=0.004$ vs. MCI-AD; ${ }^{\mathrm{g}} P=0.002$ vs. Stable MCI; ${ }^{\mathrm{h}}$ $P<0.0001$ vs. MCI-AD.

Abbreviations: $\mathrm{MMSE}=$ Mini-Mental State Examination; $\mathrm{MCI}=$ mild cognitive impairment; $\mathrm{CSF}=$ cerebrospinal fluid; $\mathrm{M}=$ men; $\mathrm{W}=$ women .

Controls were healthy individuals with stable cognitive functions during 3 years of follow-up. Stable MCI includes MCI patients with stable cognitive functions during a follow-up period of 4.0-6 8 years. MCI-AD includes MCI patients that developed Alzheimer's disease during follow-up. MCI-other includes MCI patients that developed other types of dementia during follow-up. 
Table 2. Baseline CSF levels of T-tau, P-tau $181, \mathrm{~A} \beta 42$, and A $\beta 42 / \mathrm{P}-\operatorname{tau}_{181}$ ratio.

\begin{tabular}{|l|c|c|c|c|c|}
\hline & $\mathrm{N}$ & $\mathrm{T}$-tau $(\mathrm{ng} / \mathrm{L})$ & $\mathrm{P}_{181^{-}}$-tau $(\mathrm{ng} / \mathrm{L})$ & $\mathrm{A} \beta 42(\mathrm{ng} / \mathrm{L})$ & $\mathrm{A} \beta 42 / \mathrm{P}^{-t a u}{ }_{181} \mathrm{ratio}$ \\
\hline Controls & 39 & $326 \pm 157$ & $61 \pm 17$ & $700 \pm 181$ & $125 \pm 47$ \\
\hline Stable MCI & 56 & $340 \pm 212$ & $62 \pm 16$ & $551 \pm 188^{\mathrm{a}}$ & $9 \cdot 5 \pm 3 \cdot 8^{\mathrm{a}}$ \\
\hline MCI-AD & 57 & $816 \pm 426^{\mathrm{a}, \mathrm{b}}$ & $95 \pm 29^{\mathrm{a}, \mathrm{b}}$ & $324 \pm 101^{\mathrm{a}, \mathrm{b}}$ & $3 \cdot 7 \pm 1 \cdot 6^{\mathrm{a}, \mathrm{b}}$ \\
\hline MCI-Other & 21 & $480 \pm 516^{\mathrm{c}}$ & $60 \pm 26^{\mathrm{c}}$ & $579 \pm 155^{\mathrm{c}, \mathrm{d}}$ & $10 \cdot 7 \pm 3 \cdot 9^{\mathrm{c}}$ \\
- MCI-VaD & 15 & $476 \pm 592^{\mathrm{c}}$ & $60 \pm 30^{\mathrm{c}}$ & $567 \pm 173^{\mathrm{c}, \mathrm{e}}$ & $10 \cdot 8 \pm 4 \cdot 4^{\mathrm{c}}$ \\
- MCI-DLB & 3 & $587 \pm 184^{\mathrm{f}}$ & $64 \pm 11^{\mathrm{g}}$ & $572 \pm 121^{\mathrm{h}}$ & $8 \cdot 9 \pm 1 \cdot 8^{\mathrm{c}}$ \\
- MCI-FTD & 1 & 300 & 51 & 600 & $11 \cdot 8$ \\
- MCI-SD & 1 & 828 & 81 & 760 & $9 \cdot 4$ \\
- MCI-TBI & 1 & 58 & 42 & 579 & $13 \cdot 8$ \\
\hline
\end{tabular}

Values are means $\pm \mathrm{SD}$

${ }^{\mathrm{a}} P<0.0001$ vs. Controls; ${ }^{\mathrm{b}} P<0.0001$ vs. Stable MCI; ${ }^{\mathrm{c}} P<0.0001$ vs. MCI-AD; ${ }^{\mathrm{d}} P=0.002$ vs. Controls; ${ }^{\mathrm{e}} P=0.005$ vs. Controls; ${ }^{\mathrm{f}} P=0.016$ vs. Controls; ${ }^{\mathrm{g}} P=0.024$ vs. MCI-AD; ${ }^{\mathrm{h}} P=0.009$ vs. MCI-AD.

Abbreviations: $\mathrm{CSF}=$ cerebrospinal fluid; $\mathrm{MCI}=$ mild cognitive impairment; $\mathrm{AD}=$ Alzheimer's disease; VaD = vascular dementia; DLB, dementia with Lewy bodies; FTD, frontotemporal dementia; SD, semantic dementia; TBI, traumatic brain injury-induced dementia.

Controls were healthy individuals with stable cognitive functions during 3 years of follow-up. Stable MCI includes MCI patients with stable cognitive functions during a follow-up period of 4.0-6.8 years. MCI-AD includes MCI patients that developed Alzheimer's disease during follow-up. MCI-other includes MCI patients that developed other types of dementia during follow-up. 
Table 3. Cox proportional-hazards regression models examining the relation between baseline risk factors, including CSF biomarkers, and the risk of developing AD among patients with MCI.

\begin{tabular}{|c|c|c|}
\hline & $\begin{array}{l}\text { Unadjusted Hazard } \\
\text { ratio }(95 \% \mathrm{CI})\end{array}$ & $\begin{array}{l}\text { Adjusted Hazard ratio } \\
(95 \% \mathrm{CI}) \dagger\end{array}$ \\
\hline $\begin{array}{l}\text { Pathological CSF } \\
\text { (T-tau and A } \beta 42 \text { ) }\end{array}$ & $30.0(9.32-96.8)^{\mathrm{a}}$ & $17.7(5.33-58.9)^{\mathrm{a}}$ \\
\hline $\begin{array}{l}\text { Pathological CSF } \\
\left(\mathrm{P}_{181} \text {-tau and } \mathrm{A} \beta 42\right)\end{array}$ & $26.3(8.16-84.5)^{\mathrm{a}}$ & $16.8(5.02-56.5)^{\mathrm{a}}$ \\
\hline $\begin{array}{l}\text { Pathological CSF } \\
\text { (T-tau and } A \beta 42 / \mathrm{P}_{181} \text {-tau) }\end{array}$ & $32.8(10.2-105.6)^{\mathrm{a}}$ & $19.8(5.99-65.7)^{\mathrm{a}}$ \\
\hline Age, years & $1.11(1.07-1.16)^{\mathrm{a}}$ & $1.10(1.06-1.15)^{\mathrm{a}}$ \\
\hline Female gender & $2.37(1.33-4.22)^{b}$ & $1.90(1.06-3.41)^{\mathrm{c}}$ \\
\hline$A P O E \& 4$ carrier & $2.76(1.50-5.07)^{d}$ & $2.61(1.41-4.80)^{\mathrm{e}}$ \\
\hline Higher education & $0.65(0.37-1.13)$ & $0.80(0.45-1.43)$ \\
\hline Systolic BP, mm Hg & $1.00(0.99-1.01)$ & $1.00(0.98-1.01)$ \\
\hline Diastolic BP, mm Hg & $0.97(0.95-0.99)^{\mathrm{f}}$ & $0.99(0.97-1.02)$ \\
\hline Plasma homocysteine, $\mu \mathrm{M}$ & $1.08(1.04-1.13)^{\mathrm{a}}$ & $1.08(1.04-1.12)^{\mathrm{a}}$ \\
\hline MMSE, total score & $0.87(0.75-1.02)$ & $1.02(0.85-1.21)$ \\
\hline MMSE, delayed recall & $0.67(0.51-0.88)^{b}$ & $0.85(0.64-1.13)$ \\
\hline Clock-drawing test & $0.98(0.88-1.09)$ & $0.94(0.84-1.04)$ \\
\hline
\end{tabular}

${ }^{\mathrm{a}} \mathrm{P}<0.0001 ;{ }^{\mathrm{b}} \mathrm{P}=0.004 ;{ }^{\mathrm{c}} \mathrm{P}=0.03 ;{ }^{\mathrm{d}} \mathrm{P}=0.001 ;{ }^{\mathrm{e}} \mathrm{P}=0.002 ;{ }^{\mathrm{f}} \mathrm{P}=0.01$.

All data were collected at baseline $(\mathrm{t}=0)$. Cut-off values for pathological CSF: Total-tau $>350$ ng/L; A $\beta 42<530$ ng/L; $P_{181}$-tau $\geq 60$ ng/L, A $\beta 42 /$ Ptau ratio <6.5. Abbreviations: BP, blood pressure; APOE, apolipoprotein E; MMSE, Mini-Mental State Examination (max 30 points, lower score indicates a greater number of errors); Clock-drawing test (0-10 points, lower score indicates a greater number of errors).

$\dagger$ Adjusted (if applicable) for the baseline demographic variables, age, sex, education level and $A P O E \& 4$ carrier status. 


\section{Figure legends}

\section{Figure 1}

The figure depicts the combination of T-tau and A $\beta 42$ (Panel A); the combination of P-tau 181 and $\mathrm{A} \beta 42$ (Panel B); and the combination of T-tau and A $\beta 42 / \mathrm{P}-\operatorname{tau}_{181}$ ratio (Panel C). The horizontal hatched lines represent the cut-off value for A $\beta 42$ (Panel A and B) or A $\beta 42 / \mathrm{P}$ $\operatorname{tau}_{181}$ ratio (Panel C). The vertical hatched lines represent the cut-off for T-tau (Panel A and C) or P-tau 181 (Panel B). Open circles = stable MCI; filled circles $=$ MCI patients that progressed to $\mathrm{AD}$; open triangles $=\mathrm{MCI}$ patients that progressed to other forms of dementia; open squares $=$ cognitively stable controls.

\section{Figure 2}

Example of Kaplan-Meier estimates of the rate of progression to AD in MCI subjects with either normal CSF or pathological CSF at baseline using the combination of T-tau and A $\beta 42$. Cut-off values for pathological CSF was $>350 \mathrm{ng} / \mathrm{L}$ for T-tau and $<530 \mathrm{ng} / \mathrm{L}$ for A $\beta 42$. The incidence of $\mathrm{AD}$ in MCI cases with pathological CSF $(n=67)$ was $27 \%$ per year as compared to $1 \%$ per year in patients with normal CSF $(n=67)$. Numbers at risk are the number of MCI patients at each time point that had not developed any type of dementia and where the clinical follow-up still was ongoing (numbers at risk: $\mathrm{t}=0$ months, $\mathrm{n}=134 ; \mathrm{t}=10$ months, $\mathrm{n}=131 ; \mathrm{t}=20$ months, $\mathrm{n}=111 ; \mathrm{t}=30$ months, $\mathrm{n}=87 ; \mathrm{t}=40$ months, $\mathrm{n}=74 ; \mathrm{t}=50$ months, $\mathrm{n}=55$ and $\mathrm{t}=60$ months, $\mathrm{n}=31$ ). 


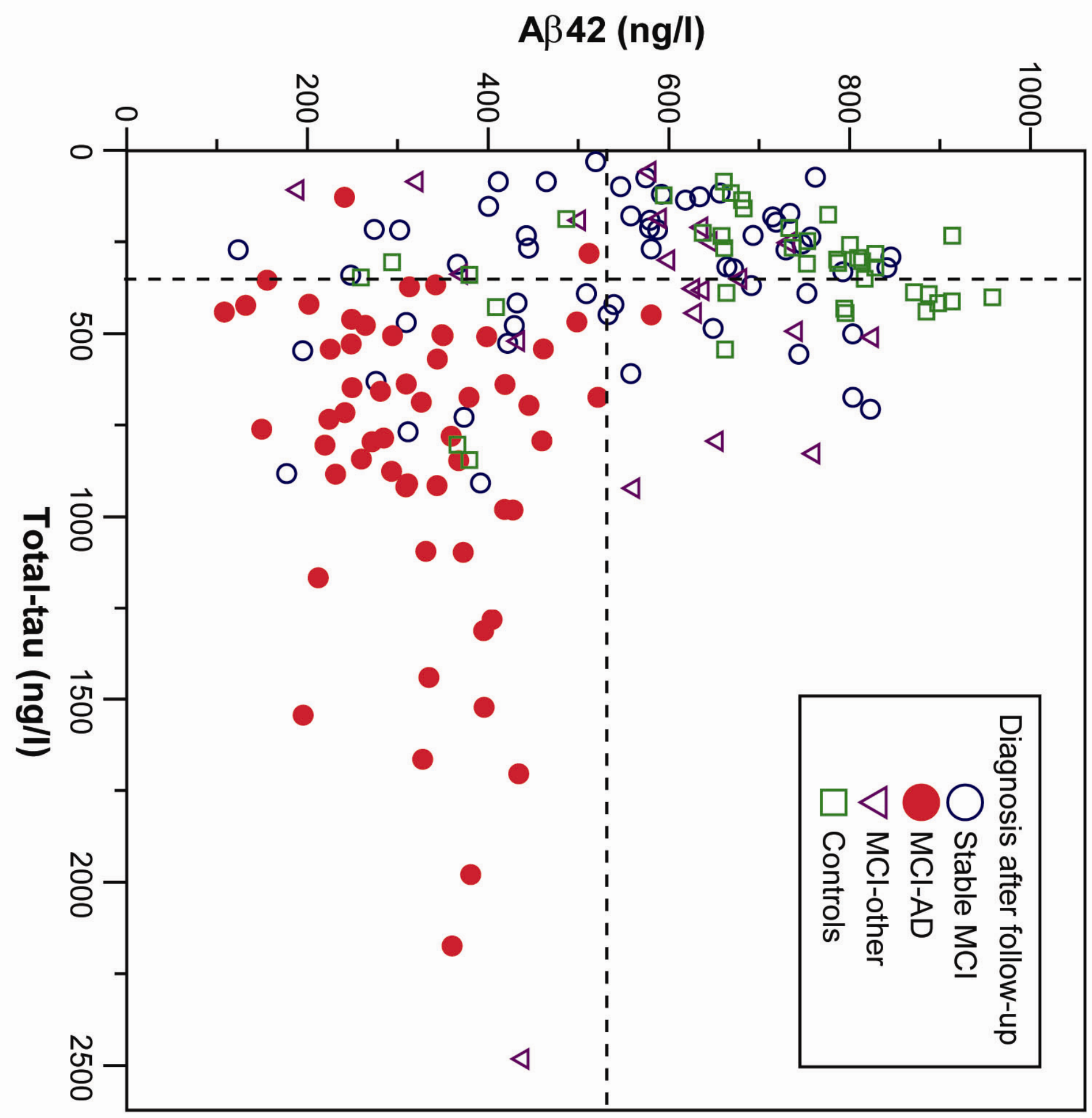




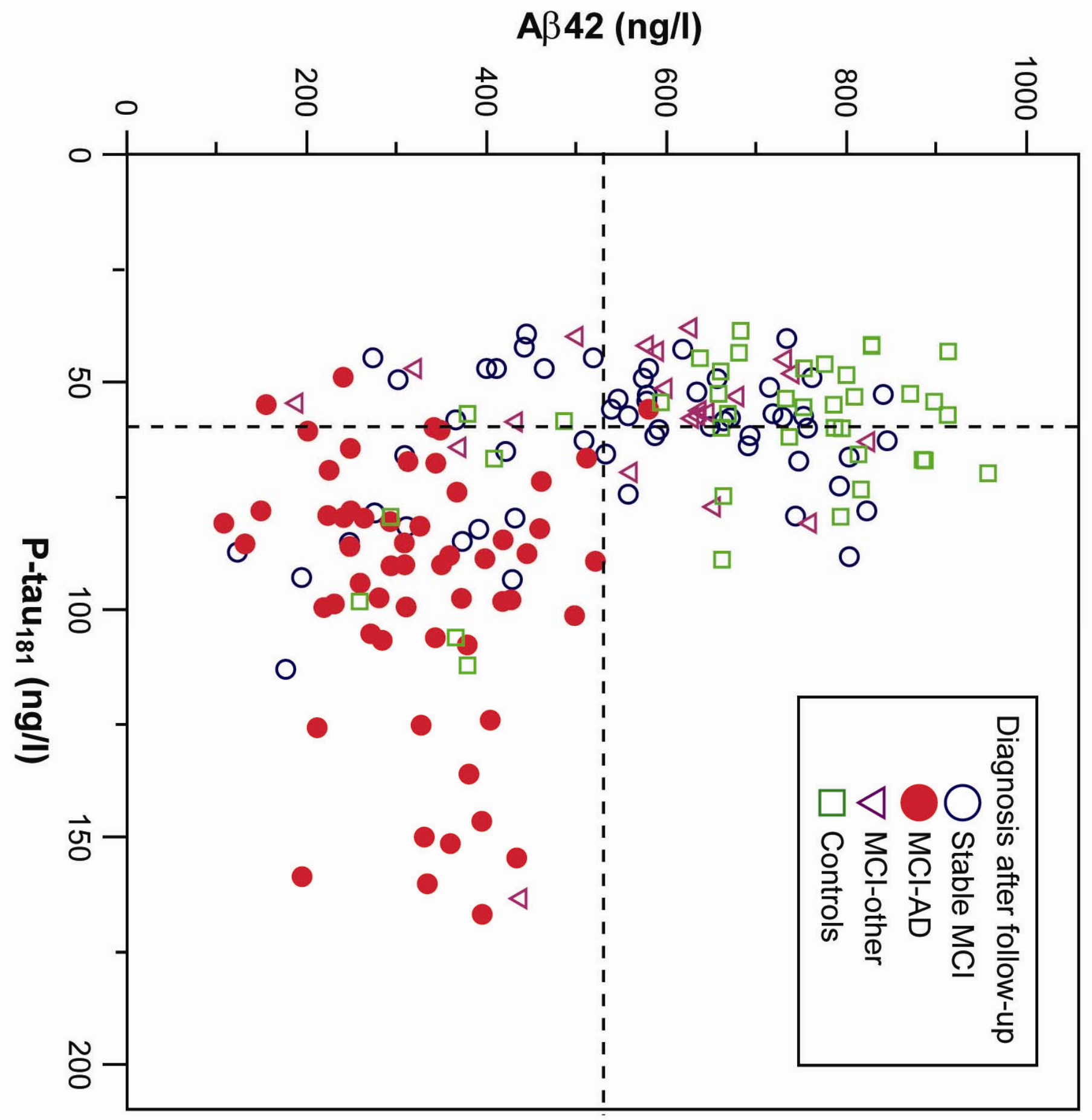




\section{A $\beta 42 / P-t_{10 u}{ }_{181}$ ratio}

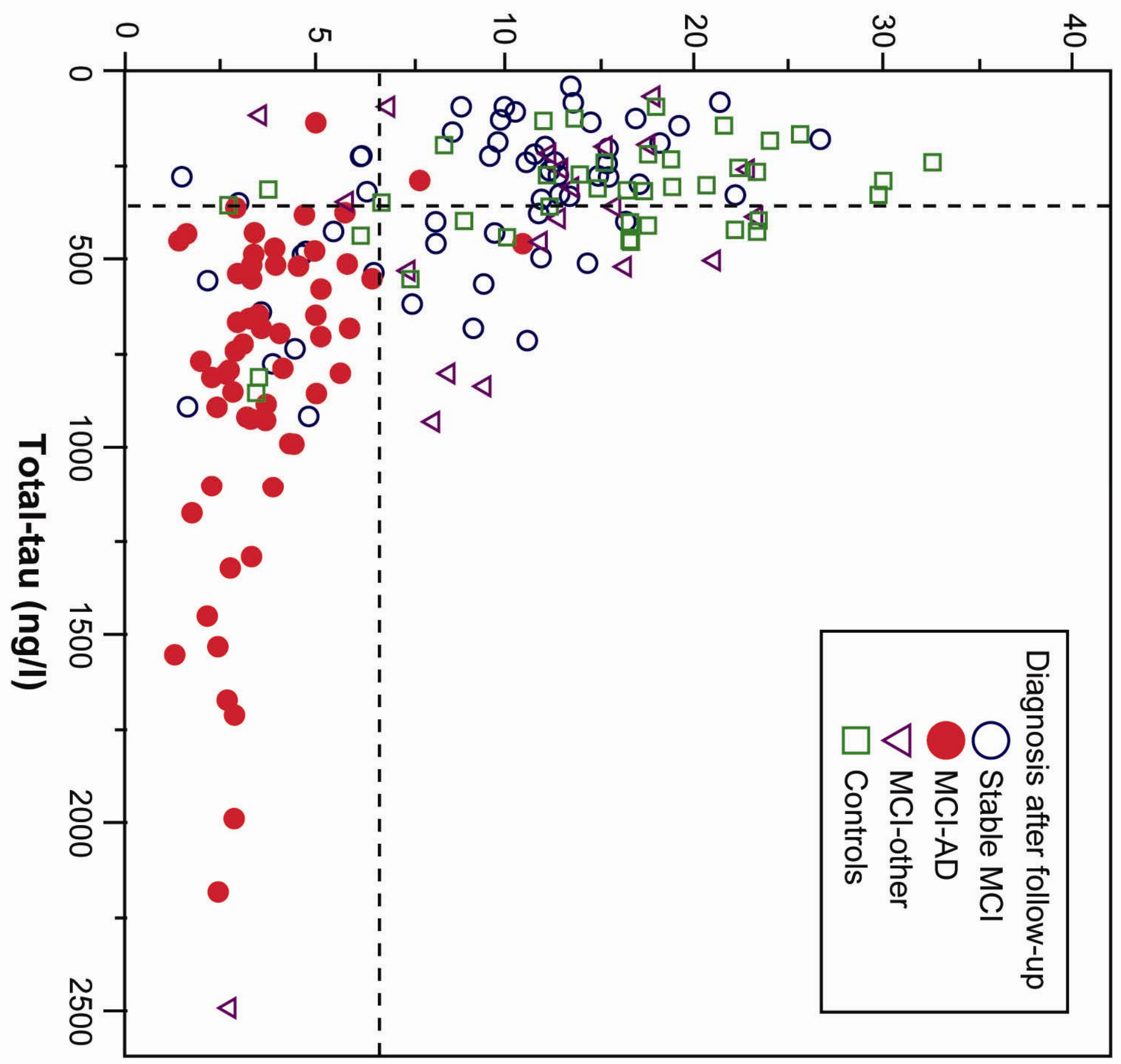


